\title{
ESTATUTO DE LOS SOCIOS COMANDITARIOS: DERECHOS Y NORMATIVA APLICABLE*
}

\author{
Ma. Fernanda Vásquez Palma**
}

\section{INTRODUCCIÓN: EXPLICACIÓN DE LOS HECHOS}

En autos seguidos ante la Juez Árbitro Ana Tampier De Jong, en juicio declarativo, Rodrigo Sánchez Carvajal, abogado, en representación de Nelson Walter King Farías, interpuso demanda contra Eugenio Correa Poblete, por sí y en representación de "Inversiones Concón Limitada Compañía en Comandita por Acciones", y de la sociedad "Inversiones Axión Limitada", sociedad gestora de la anterior.

El actor, quien detentaba la calidad de socio comanditario de la sociedad demandada, solicitó que, ante su renuncia formalizada mediante escritura pública de fecha 16 de junio del año 2008 a la sociedad "Inversiones Concón Limitada Compañía en Comandita por Acciones", se declare la expiración y disolución de dicha sociedad y se proceda a la liquidación de la misma según el artículo 38 de los estatutos sociales y se le haga entrega como titular del 12,5 por ciento del capital social equivalente a 3.150.000 acciones de Asfaltos Chile S.A. que le corresponden por estar en poder de la sociedad en comandita por acciones ya individualizada, ello en aplicación de lo dispuesto en el artículo 2108 del Código Civil.

El actor funda su derecho de renuncia y de solicitar la disolución de la sociedad en el hecho que esta última no tiene plazo de duración, ya que si bien aparece pactada por cinco años, este plazo era prorrogable automáticamente por períodos iguales y sucesivos si la gestora no daba aviso de su voluntad contraria a la prórroga, lo que hace que su término quede sujeto a una condición, esto es, a un hecho futuro e incierto que puede acaecer o no y que depende de la sola voluntad de la socia gestora, en este caso de la sociedad "Inversiones Axion

* Colaboración recibida el 10 de abril y aprobada el 25 de abril de 2013.

** Profesora Asociada de Derecho Privado Facultad de Ciencias Jurídicas y Sociales, Universidad de Talca; Doctora en Derecho por la Universidad Complutense de Madrid. Correo electrónico: mfvasquez@ utalca.cl. Este comentario se basa en la causa "King Farías, Nelson v. Inversiones Axion Ltda. y otros", pronunciada por la Primera Sala de la Excma. Corte Suprema, con fecha 26 de octubre de 2012. Base de datos Microjuris: Rol No 1008-10, MJJ33580. 
Limitada". Añade que la renuncia que presentó a la sociedad en comandita fue notificada a los socios, la formuló de buena fe y no es intempestiva.

Razona en el sentido que el artículo 491 del Código de Comercio hace aplicable a las sociedades en comandita por acciones las disposiciones de la sociedad en comandita simple, en cuanto no estén en contradicción con su regulación. Añade que el artículo 474 del mismo cuerpo legal, a propósito de la sociedad en comandita simple dispone que este tipo de sociedades se forma y prueba como la sociedad colectiva, y está sometida, además de las disposiciones especiales que la regulan, a las reglas contenidas en los siete primeros párrafos del Título VII del Libro II de dicha recopilación si no se encuentran en oposición con la naturaleza jurídica de este contrato. Aquí se encuentra precisamente el artículo 407 del Código de Comercio que dispone que la sociedad se disuelve por los modos que establece el Código Civil, de manera que resulta aplicable a la disolución a la sociedad en comandita por acciones lo dispuesto en los artículos 2098 y siguientes de este último cuerpo legal, específicamente la regla contenida en el artículo 2108 de esa codificación que facultad a los socios a renunciar a la sociedad, salvo cuando ésta se hubiere contratado por tiempo fijo o para un negocio de duración limitada. Por otra parte, considera que la sociedad en comandita por acciones es un contrato que se celebra en atención a la calidad o cualidades personales, de manera tal que el socio comanditario puede renunciar entonces a la sociedad en comandita por acciones sin expresión de causa cuando la misma se hubiere pactado a término indefinido.

En subsidio de lo anterior, para el caso que se resuelva que la sociedad se acordó por tiempo fijo o para un negocio determinado y no a una duración o vigencia indefinida, solicitó se le reconozca el derecho de provocar la disolución de la sociedad "Inversiones Concón Limitada Compañía en Comandita por Acciones" al finalizar el período actualmente en curso, en razón de que no existiría el acuerdo unánime que exigen los artículos 2098 del Código Civil y 350 del Código de Comercio para mantener vigente la sociedad, pues su intención es no renovar el plazo de duración de la sociedad y, por consiguiente, pide se declare que la sociedad gestora tiene la obligación de dar curso, en la oportunidad correspondiente, al proceso de liquidación de la compañía de conformidad con lo estipulado en el artículo 38 de los estatutos sociales haciéndosele entrega de 3.150.000 acciones de la sociedad Asfaltos Chilenos S.A. que son las que proporcionalmente le corresponden.

Si ello tampoco se le confiere, solicita que el árbitro determine la fecha y oportunidad en que debe disolverse la sociedad considerando la voluntad que expresó de ponerle término a la misma, a fin de que pueda recibir la señalada proporción de acciones de la sociedad Asfaltos Chile S.A., todo lo anterior, con costas. 
La contraparte solicitó el rechazo de la demanda con costas. Precisan que se trata de una sociedad vigente hace más de veinticinco años y que la renuncia del actor es improcedente por cuanto se estipuló expresamente que la sociedad en comandita por acciones tendría un plazo fijo de cinco años que se renovaría automáticamente por períodos iguales y sucesivos a no ser que la socia gestora manifestare su voluntad de no prorrogarla, lo que no ha acontecido. De allí entonces que al haberse pactado la vigencia de la sociedad por un plazo prorrogable automáticamente no tiene aplicación la renuncia que prevé y autoriza el artículo 2108 del Código Civil, la cual para ser válida sólo ha podido fundarse en alguno de los graves motivos taxativos que el precepto enuncia. Puntualizan que en el estatuto social no se contempló la facultad de los socios comanditarios de renunciar a la sociedad para provocar su disolución; y que la renuncia del actor fue hecha de mala fe e intempestivamente por lo que carece de valor al tenor de lo dispuesto en el artículo 2110 del Código Civil. Asimismo, solicitan el rechazo de las peticiones subsidiarias de la demanda por cuanto resultan improcedentes a la luz del pacto social.

La Juez Árbitro rechazó la demanda en todas sus partes, sin costas. Apelado ese fallo por la parte demandante, una Sala de la Corte de Apelaciones de Santiago, en sentencia de veinticuatro de diciembre de dos mil nueve la confirmó. En contra de esta última decisión la parte demandante dedujo recurso de casación en el fondo.

\section{La sentencia de la Excma. Corte Suprema}

Transcribo, a continuación, los considerandos más relevantes de este fallo y su parte resolutiva.

Octavo: Que cualquiera fuere la posición doctrinaria que se asuma en orden a resolver si el socio comanditario o accionista de la sociedad en comandita por acciones puede renunciar a la sociedad asilándose en el artículo 2108 del Código Civil, o por estar más próxima su realidad jurídica con la del accionista de una sociedad anónima negársele ese derecho, lo cierto es que en el presente caso ello carece de trascendencia desde que los jueces de la instancia han decidido que la sociedad en relación a la cual se litiga se pactó por un plazo fijo, aunque con cláusula de renovación automática por periodos iguales y sucesivos de cinco años salvo que el socio gestor manifieste su voluntad de ponerle término del modo que se regula en sus estatutos sociales.

En otros términos, si la citada disposición legal reconoce que "La sociedad puede expirar también por la renuncia de uno de los socios", pero en su inciso segundo establece claramente dos excepciones: "cuando la sociedad se ha contratado por tiempo fijo, o para un negocio de duración limitada", y los jueces de la instancia estimaron que la sociedad encuadra en la primera de las hipótesis 
de excepción al derecho absoluto de renuncia que se reconoce al socio, ésta Corte, para examinar la denunciada infracción a esa norma legal tendría que modificar el hecho así establecido, lo que no le está permitido en sede de un recurso de derecho estricto como es el que se ha deducido, toda vez que la impugnación no ataca vulneración de las denominadas leyes reguladoras de la prueba, única vía que le permitiría efectuar una ponderación fáctica diversa en ese extremo;

Noveno: Que, aún más, apreciando los sentenciadores las pruebas rendidas, concretamente la testimonial, confesional y documental, tuvieron por acreditado, en mérito de ellas, que las partes se vincularon mediante un contrato de sociedad que fue contratado por tiempo fijo, con cláusula de renovación automática, para lo cual interpretan el artículo cuarto de los estatutos sociales que, en lo pertinente señala que "La sociedad durará cinco años desde esta fecha y se entenderá prorrogada tácita y sucesivamente por periodos iguales de cinco años cada uno, salvo que el socio gestor manifieste su voluntad en contrario" del modo que en esta cláusula se regula, como también el artículo trigésimo sexto del mismo pacto social que trata de la renuncia de la sociedad gestora.

Sobre el particular es preciso considerar que este tribunal ha reiterado que la interpretación de los contratos queda dentro de las facultades propias de los magistrados de la instancia y solamente procede que sean revisados por esta Corte de Casación en cuanto se desnaturalice el contenido y alcance de la convención, con lo que se incurriría así en una transgresión a la Ley del Contrato prevista en el artículo 1545 del Código Civil, como a las disposiciones pertinentes a la interpretación de los mismos de los artículos 1560 y siguientes del citado cuerpo legal. Ello ocurriría, ciertamente, cuando se alteran las consecuencias de las cláusulas pactadas respecto de las que no existe controversia en la forma en que se consintieron, desnaturalizándolas y, en tales circunstancias, se producirá como efecto que la facultad soberana de los jueces del pleito para establecer los hechos de la causa no pueda extenderse a su apreciación jurídica y a la determinación de la ley que les sea aplicable. De suerte que para atribuirle en el presente caso un sentido y alcance diverso a aquél que le han asignado los jueces de fondo a las referidas estipulaciones contractuales, en orden a concluir que el contrato de sociedad se pactó a término o plazo indefinido y con ello entrar luego al examen de si se debía o no reconocérsele al actor-socio comanditario- el derecho a renunciar a la sociedad sin expresión de causa y en cualquier tiempo, la impugnación debió denunciar eficientemente infracción de las normas de interpretación de los contratos, omisión, que unida a la anterior, impide a esta Corte verificar ese examen;

Décimo: Que, por consiguiente, no se divisa como podrían estimarse vulnerados los artículos $2^{\circ}, 491,474$ y 407 del Código de Comercio relativos a las 
"Estatutos de socios comanditarios: Derechos y normativa aplicable"

normas aplicables a las sociedades en comandita por acciones, en relación con el artículo 19 del Código Civil en materia de interpretación y con el artículo 1545 de este último cuerpo normativo, si más allá del razonamiento que Ilevó a los jueces de la instancia a no reconocerle el derecho al actor-socio comanditario- a renunciar a la sociedad "Inversiones Concón Limitada Compañía en Comandita por Acciones" no se ha establecido el supuesto fáctico exigido por el artículo 2108 del Código Civil para que, en la hipótesis que la impugnación sostiene-que el socio comanditario se debe homologar al socio de la sociedad colectiva y no al del accionista de una sociedad anónima- pueda admitirse que aquél puede renunciar a la sociedad, en cualquier tiempo sin expresión de causa, desde que ha quedado establecido, con carácter inamovible en esta sede al no haberse denunciado infracción a las denominadas leyes reguladoras de la prueba y a las normas sobre interpretación de los contratos, que la referida sociedad es de duración indefinida, único caso en que la precitada disposición legal reconoce ese derecho en términos absolutos;

Décimo Primero: Que enseguida, en un segundo capítulo el recurso en examen denuncia la infracción de diversas normas del Código de Comercio, de la Ley de Sociedades Anónimas y del Código Civil, todas ellas encaminadas a demostrar que los jueces del grado yerran al homologar el estatuto jurídico que gobierna la relación del socio comanditario de la sociedad en comandita por acciones con el del accionista de la sociedad anónima. Concretamente, los artículos 480, 491 y 495 del Código de Comercio relativos a la responsabilidad de los socios comanditarios, su artículo 476 referido a las limitaciones de los socios gestores, los artículos 8, 31 y 25 de la Ley de Sociedades Anónimas en cuanto al nombre, administración y suscripción de acciones en este tipo de sociedades, los artículos 498, 500 y 502 en relación a la Junta de Vigilancia de la sociedad en comandita por acciones, el artículo 481 del Código de Comercio en cuanto a los derechos del socio comanditario, el artículo 55 de la ley № 18.046 en relación a las Juntas de Accionistas de las sociedades anónimas, los artículos 482, 494 y 495 del Código de Comercio referidos a la cesión de acciones de las sociedades en comandita por acciones, el artículo 2070 del Código Civil en cuanto a la distribución de beneficios y pérdidas, los artículos 477, 485, 498, 501 y 502 del Código de Comercio relativos a las limitaciones al nombre y administración de los socios comanditarios y de las sociedades en comandita por acciones y, finalmente, el artículo 2061 Código Civil que distingue entre sociedades colectivas y en comandita;

Décimo Segundo: Que aun cuando los razonamientos que se contienen en el fallo impugnado fueren errados, al asimilar a los socios comanditarios por acciones con los accionistas de las sociedades anónimas para concluir que el socio comanditario de la sociedad en comandita por acciones no puede renunciar a ella, al igual que el accionista de la sociedad anónima, lo cierto es que tal 
análisis carece de toda influencia en lo que viene resuelto por las consideraciones ya expuestas en los motivos sexto a décimo de la presente sentencia.

Con todo, no está demás reiterar que tal como se relacionó en el considerando quinto de este fallo, la doctrina autorizada discrepa en torno al estatuto jurídico que le resulta aplicable al socio comanditario de la sociedad en comandita por acciones, desde que la finalidad societaria que lo anima se avendría más con la propia del accionista de una sociedad anónima en algunos aspectos que con la del socio de una sociedad colectiva, aunque para la resolución de la presente impugnación debe insistirse ello carece de trascendencia por lo que ya se ha razonado;

Décimo Tercero: Que, por consiguiente, resulta indiferente examinar si el socio comanditario tiene la misma responsabilidad y derechos que el derogado artículo 456 del Código de Comercio otorgaba a los accionistas de la sociedad anónima, si se ha desconocido que la sociedad en comandita por acciones es una sociedad especial, sui generis, con existencia propia, por reconocerlo así el legislador en los artículos 491 en relación con el artículo 348 №3, ambos del Código de Comercio, y el artículo 2061 del Código Civil, desde que el artículo 476 del Código de Comercio contempla una limitación para los socios comanditarios en orden a figurar en la razón social y ejecutar actos de administración que no existen para los accionistas de las sociedades anónimas, o si corresponde asimilar la Junta de Vigilancia y las Asambleas Generales de las sociedades en comandita por acciones con los órganos de administración propios de las sociedades anónimas, extremos todos que pueden ser discutibles, puesto que el derecho absoluto que el actor reclama de renunciar a su condición de socioaccionista de la sociedad en comandita no se lo reconoce el artículo 2108 del Código Civil habida cuenta de que los jueces de la instancia han dejado establecido que la sociedad "Inversiones Concón Limitada Compañía en Comandita por Acciones" se pactó por un plazo fijo y no a término indefinido;

Décimo Cuarto: Que tampoco se divisa como podrían haberse vulnerado los artículos 2065 y 2098 en relación con los artículos 1494 y 1473, todos del Código Civil, porque los jueces del fondo concluyeron que en el estatuto social los socios pactaron un plazo de duración de la sociedad, pues tal es un hecho inamovible que, por las consideraciones ya expuestas no puede ser alterado $y$, como se ha dicho en este fallo, no determina las calificaciones jurídicas del estatuto jurídico aplicable al socio comanditario de la sociedad en comandita por acciones desde que el efecto de la renuncia unilateral del actor a su calidad socio en todo caso no podría serle reconocido porque dicha sociedad no es duración indeterminada;

Décimo Quinto: Que se denuncia también la infracción a los artículos 2108, 2109, 2110, 2111 y 2112, todos del Código Civil, que regulan la renuncia de los socios, al concluirse que la misma no puede operar en este caso, lo que 
contraviene la ley. Tales disposiciones, insertas en la normativa que regula la sociedad colectiva civil, establecen que la sociedad puede expirar por la renuncia de uno de los socios cuando la sociedad se hubiere contratado a duración indefinida, por grave motivo, como la inejecución de las obligaciones de otro socio, la pérdida de un administrador inteligente que no pueda reemplazarse entre los socios, enfermedad habitual del renunciante que lo inhabilite para las funciones sociales, mal estado de sus negocios por circunstancias imprevistas, u otros de igual importancia, como también regula la forma en que debe formalizarse, sus efectos y el caso en que la misma deba estimarse se hizo efectiva de mala fe;

Décimo Sexto: Que aun cuando las citadas disposiciones reconocen el derecho del socio a renunciar a la sociedad y fueren aplicables en el presente caso, se advierte que tal prerrogativa no puede ejercerse sino en los casos y en la forma que allí se regula, esto es, cuando la sociedad se hubiere pactado a duración indefinida o se acreditare la concurrencia de algún "grave motivo" como los que enuncia el artículo 2108 de esa codificación, pero en ningún caso, como dice esa norma, "si por el contrato no se hubiere dado la facultad de hacerla". Ocurre, pues, que ha quedado establecido que el pacto social no reconoce ese derecho, como se infiere de los artículos cuarto y trigésimo sexto del estatuto social, de suerte que al concurrir la hipótesis legal que la autoriza no podría haberse infringido la señalada normativa;

Décimo Séptimo: Que en este punto el recurrente cuestiona que tal derecho se le hubiere reconocido en los estatutos sociales únicamente al socio gestor y no a los comanditarios. Sin embargo, el examen de la estipulación trigésimo sexto del pacto social permite observar que no se trata de un derecho de ejercicio discrecional el que se le reconoce al socio gestor, desde que sólo puede renunciar por "motivos muy graves y calificados" lo que debe aprobar una asamblea extraordinaria de socios.

Sin perjuicio de ello, una estipulación tal es fruto del acuerdo social alcanzado al amparo del principio de la autonomía de la voluntad, esto es de la "La libertad de que gozan los particulares para pactar los contratos que les plazcan, y de determinar su contenido, efectos y duración", como lo apunta el Profesor Arturo Alessandri en su clásica obra sobre Los Contratos, o como lo señala el profesor Jorge López Santa María: "El principio de la autonomía de la voluntad es una doctrina de filosofía jurídica según la cual toda obligación reposa esencialmente sobre la voluntad de las partes. Esta es, a la vez, la fuente y la medida de los derechos y de las obligaciones que el contrato produce", como lo indica en su texto sobre Los Contratos, Parte General. Siendo esto así, quiere decir que la autonomía de la voluntad se basa en los principios propios de la ilustración de la libertad y de la igualdad, que llevados ambos al plano jurídico, se traducen en igualdad y libertad jurídica de las partes, libertad que 
se divide a su vez en la libertad para contratar, que es la libertad para celebrar o no el contrato y con quién, y la libertad contractual, que es la libertad para fijar los términos o contenidos del contrato.

Tal es precisamente lo que las partes acordaron al reconocerle al socio gestor el derecho a renunciar en los casos y forma que se regula en los estatutos sociales;

Décimo Octavo: Que en un quinto capítulo la impugnante denuncia la vulneración del artículo 350 del Código de Comercio en relación con el artículo 2098 del Código Civil, desde que los sentenciadores no le reconocieron en su condición de socio comanditario el derecho que las citadas disposiciones legales le otorgan para expresar su voluntad de no renovar la vigencia de la sociedad o, en otros términos, para oponerse a que la sociedad se prorrogue automáticamente en su vigencia al finalizar el plazo por el cual se acordó;

Décimo Noveno: Que aun cuando es efectivo que tal prerrogativa los estatutos sociales únicamente la admiten para que sea ejercida por el socio gestor, pero no por los comanditarios-accionistas, ello se explica o es consecuencia simplemente de la manifestación la voluntad de las partes, que acuerdan libremente vincularse por un contrato de sociedad que contiene esas estipulaciones. En suma, en este extremo ha operado el principio de la autonomía de la voluntad contractual.

Lo que en verdad subyace detrás de este reproche en la impugnación, es que el recurrente no acepta que tal prerrogativa -la facultad de poner término a la sociedad al finalizar el plazo acordado- se le hubiere reconocido únicamente al socio gestor, pero no a los comanditarios-accionistas. Sin embargo, ello no puede estimarse discriminatorio por sí mismo y que una estipulación tal vulnere disposiciones de orden público y, consiguientemente declarar que es nula para igualar en el ejercicio de ella al socio gestor con el comanditario.

Por lo pronto debe convenirse que los fines que motivan la participación de uno u otro socio en la sociedad en comandita por acciones es sustancialmente diverso, tanto en los aportes que efectúan como en los derechos y obligaciones que asumen, lo que basta para justificar el diverso trato que la ley les dispensa.

Se sigue de ello que una diferenciación tal en el ejercicio de esa prerrogativa no parece irracional, atiende a fines lícitos y es proporcionada, por lo que no habiéndose además denunciado -con el rigor de especificidad que se exigen sede de casación- qué normas de orden público resultarían quebrantas con esa estipulación, esta Corte está impedida de realizar este examen;

Vigésimo: Que en un último apartado, la recurrente insiste en la infracción del artículo 470 del Código de Comercio que define la sociedad en comandita por acciones y del artículo 2065 del Código Civil en relación al plazo de la sociedad, ya que al no haberse estipulado plazo se debiera entender a salvo, en 
su opinión, el derecho del socio a la renuncia, mientras que el artículo 2108 del precitado cuerpo legal se infringiría porque en mismo reconocería un derecho absoluto a renunciar a la sociedad a todos los socios, sin distinguir, lo que a él, en cuanto socio comanditario, le es negado.

Para desestimar que tales disposiciones hubieren sido quebrantas por los sentenciadores, basta considerar que nuevamente la impugnación se apoya en un supuesto fáctico no establecido -que "Inversiones Concón Limitada Compañía en Comandita por Acciones" es una sociedad pactada a término indefinido y que la discriminación entre los socios gestores y los comanditarios carece de justificación, lo que ha sido descartado precedentemente;

Vigésimo Primero: Que, en virtud de los razonamientos precedentemente desarrollados, no cabe sino concluir que la sentencia que se revisa no ha incurrido en los errores de derecho que le atribuye el recurso analizado por lo cual debe ser desestimado.

Y de conformidad, además, con lo dispuesto en los artículos 764, 765, 767, 805, 806 y 808 del Código de Procedimiento Civil, se rechaza el recurso de casación en el fondo interpuesto por la parte demandante en lo principal del escrito de fojas 377 , en contra de la sentencia de veinticuatro de diciembre de dos mil nueve, escrita a fojas 376.

Regístrese y devuélvase con sus agregados.

Redacción del Abogado Integrante señor Emilio Pfeffer Urquiaga.

No 1008-10.

Pronunciado por la Primera Sala de la Corte Suprema por los Ministros Sres. Nibaldo Segura P., Juan Araya E., Juan Fuentes B., Alfredo Pfeiffer R. y Abogado Integrante Sr. Emilio Pfeffer.

En Santiago, a veintiséis de octubre de dos mil doce.

\section{Comentarios sobre el caso y la Sentencia}

Son escasos los fallos que se han pronunciado sobre esta materia, de manera que me parece una sentencia muy interesante y oportuna de analizar en tanto contribuye a la discusión y el correcto entendimiento de la institución societaria que está viviendo un especial proceso de maduración. Empero, dado lo acotado de un trabajo de esta naturaleza, sólo observaré y subrayaré los aspectos que estimo de mayor relevancia, dejando otros necesariamente de lado en aras de no extenderme más allá de lo prudente.

En tal sentido, el centro de atención en este caso reside en el estatuto jurídico aplicable a los socios comanditarios, lo que incide necesariamente en la delimitación de sus derechos. El recurrente razona y sostiene que a partir de las normas que regulan a la sociedad por acciones debieran aplicarse el Código de Comercio, en lo relativo a la sociedad colectiva, y el Código Civil, 
fundamentalmente el artículo 2108 que determina los casos en que es válida la renuncia del socio. En su consideración, tal precepto es aplicable a ambos tipos de socios "gestores y comanditarios", en razón de que en la citada normativa nada se distingue sobre el particular.

En la discusión se aprecian diversos argumentos que coadyuvan a resolver el caso, el más relevante de ellos residió en la duración de la sociedad, hecho que importaba impedir la aplicación del artículo 2108 del CC, que sólo es admisible para las sociedades de duración indefinida.

En mi opinión este caso debió resolverse bajo un único hilo conductor: la naturaleza de los socios comanditarios, pues este solo argumento habría bastado para no dar lugar a la aplicación del precepto en referencia. Paso a explicar lo anterior:

\section{a) Normas aplicables a la sociedad en comandita por acciones}

Los preceptos que regulan a este tipo societario no son claros ni concluyentes, lo que propiciado un escenario nebuloso que la discusión doctrinaria ha intentado zanjar. En efecto, la sociedad en comandita, tiene reconocimiento explícito en nuestro ordenamiento jurídico en los artículos 2061, 2062 y 2063 del Código Civil y en el Código de Comercio en los párrafos $9^{\circ}, 10^{\circ}$ y $11^{\circ}$ del Título VII del Libro II, que establecen disposiciones relativas a la sociedad en comandita (artículos 470 a 473), a la en comandita simple (artículos 474 a 490) y a la en comandita por acciones (artículos 491 a 506), respectivamente. Esta última legislación se inspiró en la ley francesa de 23 de julio de 1856, tal como se deja constancia en el Mensaje del Código de Comercio. El referido cuerpo legal dice que la sociedad en comandita "es la que se celebra entre una o más personas que prometen llevar a la caja social un determinado aporte y una o más personas que se obligan a administrar exclusivamente la sociedad por sí o sus delegados y en su nombre particular. Llámese los primeros socios comanditarios y los segundos gestores" (artículo 470 del Código de Comercio).

Como sabemos, el elemento más característico de este tipo social lo constituye el contar con dos tipos o clases de socios: el o los socios gestores a quienes les cabe privativamente el uso de la razón social y la administración de la compañía, los cuales responden de las deudas sociales, y el o los socios comanditarios o capitalistas, que no responden de las deudas sociales y se los excluye de toda injerencia en la administración de la sociedad. Dada las características del socio gestor, éste no puede retirarse de la sociedad sino mediante reforma de estatutos y con el consentimiento unánime de los comanditarios. Respecto de la sociedad en comandita por acciones, el Código de Comercio precisa que "se constituye por la reunión de un capital dividido en acciones 
o cupones de acción y suministrado por socios cuyo nombre no figura en la escritura social" (artículo 473).

Las sociedades en comandita por acciones, a diferencia de las sociedades en comanditas simples, no se encuentran enunciadas en el Código Civil, de manera que su carácter siempre es mercantil. Con todo, se les aplica supletoriamente y en lo no previsto en su regulación específica, según lo establece el artículo 491 del Código del ramo, las normas legales que rigen para la sociedad en comandita simple mercantil, pero también las reglas de la sociedad colectiva comercial en cuanto no se opongan a su naturaleza, como lo preceptúa por reenvío el artículo 474 del Código de Comercio y, en último término, la normativa del Código Civil sobre sociedades, obligaciones y contratos.

Debido a la escueta regulación existente, se advierte con facilidad la existencia de un gran vacío normativo en esta materia. Así, por ejemplo, el legislador nada señala sobre los derechos del socio comanditario de la sociedad en comandita por acciones, las características de la acción y su forma de transferencia, lo que ha originado dudas acerca de qué estatuto jurídico corresponde aplicar a dichos socios. Desde mi perspectiva, tal inquietud debiera ser resuelta considerando y diferenciando la naturaleza jurídica de los socios comanditarios.

\section{b) Naturaleza de los socios comanditarios}

Las notas que diferencian a esta sociedad de la anónima son variadas: la constitución de la sociedad; la conformación de la razón social y la imposibilidad de los socios comanditarios de figurar en ella; los órganos existentes en las sociedades en comanditas por acciones que no se condicen con los de las sociedades anónimas; la responsabilidad de los comanditarios que eventualmente podrían ser alcanzados por los acreedores de la sociedad al igual que los gestores en los supuestos descritos en el Código de Comercio, esto es, por realizar actos de administración o tolerar la inserción de su nombre en la razón social. A ellas debemos agregar los derechos de los socios, toda vez que en las sociedades en comanditas por acciones la administración corresponde por ley al gestor, norma que se entiende inmodificable, de manera que el comanditario no tiene posibilidad de elegir a un administrador distinto'; en las anónimas, en cambio, se ofrece a los capitalistas mayores garantías al poder ellos designar a los administradores.

\footnotetext{
1 De allí que la ley haya previsto que el control de los socios comanditarios se ejerce en la asamblea y a través de la junta de vigilancia, entidad a la que se le reconoce la facultad de provocar la disolución de la compañía solicitándolo al tribunal correspondiente en base a alguna de las causales legales que establece el artículo 500 del Código de Comercio.
} 
En cuanto a las similitudes entre los comanditarios de las sociedades en comanditas por acciones y los accionistas de las sociedades anónimas, observamos, en primer lugar, el hecho que el aporte se divide en acciones en ambos casos, de manera que podría sostenerse que su forma de cesión es muy similar; por su parte, respecto de la disolución, las causales que afectan a los comanditarios o accionistas no empecen la continuidad de la sociedad, toda vez que en caso de fallecimiento, quiebra o incapacidad del socio, ello no tendrá consecuencias para la existencia de la sociedad.

Estos últimos puntos poseen una innegable relevancia en orden a dilucidar la inquietud planteada en el presente caso, toda vez que -a pesar de la inexistencia de una norma concreta sobre el particular- es posible sostener que respecto de los socios comanditarios debieran aplicarse supletoriamente las normas contenidas en la Ley № 18.046 sobre Sociedades Anónimas ${ }^{2}$ y no las relativas a las sociedades colectivas. En otras palabras, para los comanditarios la sociedad debe entenderse de capitales y para los gestores de personas ${ }^{3}$.

En este contexto, resulta acertado el fallo de instancia en cuanto allí se sostuvo que procedía homologar los derechos y obligaciones de los socios comanditarios de las sociedades en comandita por acciones con los de los accionistas de las sociedades anónimas, concluyendo que no le asistía al demandante la facultad de renunciar a la sociedad Inversiones Concón Limitada Compañía en Comandita por Acciones, de la forma establecida por el artículo 2108 del Código Civil, por cuanto ésta última norma contenía una causal de disolución (renuncia sin expresión de causa del socio y en cualquier tiempo) que se aplica únicamente respecto de las sociedades de personas.

De este modo, la sociedad en comandita por acciones es una sociedad mercantil sui géneris de carácter mixto, en que coexisten estos dos tipos de socios, a los que deben aplicarse -frente a la una ausencia de una normativa clara y completa- las normas relativas de las sociedades análogas a su fisonomía ${ }^{4}$.

${ }^{2}$ La doctrina es mayoritaria en este punto. A modo de ejemplo, véase: PuGA V., Juan Esteban, La sociedad anónima y otras sociedades por acciones en el derecho chileno y comparado, Ed. Jurídica de Chile, $1^{\text {a }}$ Ed., 2011, p. 742; Villegas, Carlos Alberto, Tratado de la Sociedades, Ed. Jurídica de Chile, $1^{\text {a }}$ Ed., 1996, p. 253; Morand Valdivieso, Luis, Sociedades, Ed. Jurídica de Chile, $1^{a}$ Ed., 1994, p. 58; Fernández VILLAMAYOr, Ángel, El régimen legal de la sociedad anónima en Chile, Ed. Jurídica de Chile, $2^{\text {a }}$ Ed., 1977, p. 13; SAndoval LóPEZ, Ricardo, Derecho Comercial, sociedades de personas y de capital, tomo I, Ed. Jurídica de Chile,7ª Ed., 1977, p. 83, y VÁsquez PalmA, M. Fernanda, Sociedades. Comerciantes, empresas, grupos de empresas y otros sujetos del Derecho Comercial, Ed. LegalPublishing-Thomson Reuters, pp. 454-458.

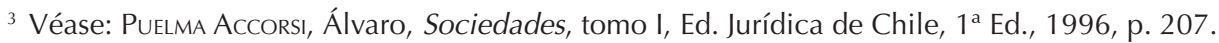

${ }^{4}$ Véase arts. 103 y siguientes de la ley $\mathrm{N}^{\circ} 18.046$. 
"Estatutos de socios comanditarios: Derechos y normativa aplicable"

c) Posibilidad de renuncia a partir de lo dispuesto en el artículo 2108 del Código Civil

Los sentenciadores resuelven teniendo presente que la disposición en comento plantea la posibilidad de renuncia sólo cuando éstas tuvieren una duración indefinida, lo cual no se verifica en la especie, pues en los estatutos sociales se pactó que su duración era de plazo fijo (cinco años), con cláusula de renovación automática, de manera que no era posible su aplicación.

Este es el principal argumento que se utiliza para resolver el caso relatado, por lo que la Excma. Corte Suprema soslaya el análisis del punto precedente (naturaleza del socio comanditario), señalando que este punto carece de toda significación a la luz de las sentencias pronunciadas por la instancia.

Como adelanté, considero que este último fundamento posee una importancia residual, y no pudo ser visto -como se hizo finalmente- de forma concluyente, toda vez que aun cuando la sociedad hubiere sido pactada con un plazo indefinido habría de llegarse a idéntico resultado, pues a este tipo de accionistas (comanditarios) no podría aplicarse una norma que está pensada para las sociedades de personas, como ocurre con dicho precepto.

\section{d) Primacía de los pactos sociales}

Finalmente, los sentenciadores argumentan que los estatutos de la sociedad contemplaron expresamente que la renuncia sólo podría efectuarse por la socia gestora, por lo que no es posible reconocer al actor el derecho de provocar la disolución de la compañía en comandita por acciones, ni declarar la fecha y oportunidad en que se disuelve. Se razona en este punto en pos del valor de la autonomía de la voluntad y de la fuerza vinculante de todo contrato.

Desde mi perspectiva, al igual que con el argumento antes citado, cabe relevar la importancia de este asunto, pues aun cuando tal materia no hubiese estado tratada categóricamente en los estatutos, debía llegarse al mismo resultado toda vez que, por la propia naturaleza de los socios que conforman este tipo social, sólo a los gestores cabría la posibilidad de renuncia, a diferencia de los comanditarios que pueden en último caso ceder sus acciones.

Bajo esta misma línea de comprensión, la pregunta que aquí surge es si los socios podrían, en base a su autonomía de la voluntad, prever que ambos tipos de socios pueden renunciar a la sociedad bajo ciertos supuestos y ello provocar la disolución de la sociedad. A diferencia de lo que señala la Excma. Corte, que así parece entenderlo, considero que esto no es posible, pues aun cuando la ley no sea categórica ni clara sobre este particular, si pensamos en la naturaleza de los socios que conforman esta sociedad, necesariamente debemos sostener que sólo los gestores podrían renunciar a la sociedad. Sostener lo contrario implicaría desnaturalizar la sociedad en comandita que Ilegaría a 
tener un solo tipo de socios (gestores/colectivos) y ello es justamente lo que el legislador no pretendió al crear este tipo societario. En otras palabras, tal naturaleza constituiría un bloque que inhibiría a los particulares en orden a la expresión de su voluntad.

En tal sentido, debe recordarse que en el caso de las sociedades anónimas no está prevista como causal de disolución la renuncia de uno o más de sus accionistas. Si bien la Ley de Sociedades Anónimas admite que los propios socios estipulen otros acontecimientos como causales de disolución, esta facultad admite ciertas limitaciones toda vez que no se puede desnaturalizar a la sociedad por medio de estas causales. A mayor abundamiento, debe considerase que éstas deben estar previstas en beneficio de la sociedad y no de algunos accionistas en particular ${ }^{5}$.

\section{e) Fuerza obligatoria del contrato y su interpretación}

El recurrente considera vulnerados los artículos $2^{\circ}, 491,474$ y 407 del Código de Comercio relativos a las normas aplicables a las sociedades en comandita por acciones, en relación con el artículo 19 del Código Civil en materia de interpretación y con el artículo 1545 de este último cuerpo normativo, que contiene el principio de la fuerza obligatoria del contrato. La infracción se produciría porque el considerando décimo cuarto de la sentencia impugnada desatiende la preceptiva legal referida y los estatutos sociales, al estimar que a los derechos de los socios comanditarios por acciones no se les aplican las disposiciones que regulan su disolución previstas en los artículos 2098 al 2115 Código Civil.

En este contexto, el recurrente sostiene que el estatuto social reenvía, en lo no previsto en sus estipulaciones, a la regulación contenida en el Código Civil y el Código de Comercio, y este último cuerpo legal contiene el artículo 491 que hace aplicable a la sociedad en comandita por acciones la regla del artículo 474 prevista para la sociedad en comandita simple que, a su vez se remite y sujeta a lo dispuesto en el artículo 407 que regula la disolución de la sociedad colectiva comercial a las causales o modos que determina el Código Civil, todo lo cual regiría en virtud del mandato que fluye del artículo $2^{\circ}$ del Código de Comercio. De allí, entonces, que si entre las normas de disolución del Código de Bello están las de los artículos 2098 a 2115, y entre ellas la del artículo 2108, resultaba ineludible concluir que la renuncia del socio comanditario de una sociedad en comandita por acciones trae aparejada la disolución de la sociedad.

$\mathrm{Al}$ respecto, me remito a lo ya relatado en tanto las normas aplicables no podrían ser las descritas para los socios comanditarios en atención a su natu-

${ }^{5}$ Con mayor detalle: Vásquez Palma, M. Fernanda, Sociedades, cit. nota n. 2, p. 725. 
raleza jurídica, de manera tal que -a pesar del vacío existente en la materia y las normas que regulan el particular- las normas del Código Civil y del Código de Comercio contempladas para los socios gestores no podrían ser aplicables a los socios comanditarios.

\section{UNA REFLEXIÓN FINAL}

El fallo comentado sucintamente deja en evidencia al menos dos cosas: el insuficiente tratamiento normativo que existe sobre las sociedades en comanditas por acciones en la legislación chilena; y -a causa de ello- la equívoca comprensión de las normas que pueden ser aplicables a los socios comanditarios y que delimitan sus derechos.

En este contexto, debiera velarse de lege ferenda por la reconstrucción normativa de este tipo societario en sus aspectos más relevantes, como ocurre con las causales de disolución de la sociedad, los derechos de los socios y sus posibilidades de actuación. En este contexto, quizás podría pensarse en el establecimiento del clásico derecho de renuncia para los socios comanditarios, justificado en situaciones concretas, como ocurre en el caso de las sociedades anónimas. Además de facilitar la comprensión, interpretación, y aplicación de dicho estatuto, se conseguiría un mayor grado de uniformidad en tales razonamientos. 